\title{
Adaptive Tabu Search Optimization Applied on Fuzzy Logic DC Motor Speed Control
}

\author{
Amer Mohammad Jarjees \\ Electrical, Department, \\ Engineering \\ University of Mosul \\ Mosul-IRAQ
}

\author{
Omar Turath Tawfeeq \\ Electrical, Department, \\ Engineering \\ University of Mosul \\ Mosul-IRAQ
}

\author{
Ali Abbawi Mohammed \\ Alabbawi \\ Electrical, Department, \\ Engineering \\ University of Mosul \\ Mosul-IRAQ
}

\begin{abstract}
In this work, two different types of controllers has been used, the first one is presents the application of fuzzy logic for DC motor speed control using Adaptive Tabu Search optimization and the second is Ziegler-Nlchols methods for PID controller tuning.
\end{abstract}

A comparative study was done for two type of controllers, namely adaptive tabu search based tuning of fuzzy controller (Fuzzy-ATS) and Ziegler- Nichols methods for PID controller tuning to control of nonlinear drive.

The work main objective is to obtain best performance of the system in both transient and steady state response represented by, minimum settling time and minimum overshoot under various conditions such as : change in load, change in speed and change in both load and speed of the motor .

\section{General Terms}

The intelligent optimization technique of Adaptive Tabu Search (ATS) is proposed to tune the fuzzy controller parameters to get optimal results of close loop of Fuzzy ATS Controllers while, Ziegler- Nichols methods for tuning PID controller is represented as a point comparison.

The system is simulated using Matlab/Simulink GUI environment and the results is discussed. The result shows that Fuzzy - ATS controllers perform well by providing the best transient and steady state DC motor speed response.

\section{Keywords}

Adaptive Tabu search, DC motor, Fuzzy Controller, Optimal Control.

\section{INTRODUCTION}

The speed of DC motor can adjusted to a great extent to provide easy control and high performance $[1,2]$. There are several conventional and numeric controller types intended for controlling the DC motor speed at its executing various tasks: PID Controller, Fuzzy Logic Controller; or the combination between them: Fuzzy-Swarm, Fuzzy-Neural Networks, Fuzzy-Genetic Algorithm, Fuzzy-Ants Colony.

Fuzzy theory would first proposed and investigated by Prof. Zadeh in 1965.

Fuzzy logic will expressed by means of if-then rules with the human language. In the design of a fuzzy logic controller, the mathematical model is not necessary. Therefore, the fuzzy logic controller is of good robustness. Owing to its easy application, it has been widely used in industry. However, the rules and the membership functions of a fuzzy logic controller will based on expert experience or knowledge database
Much work has done on the analysis of fuzzy control rules and membership function parameters [3]. The ATS (Adaptive Tabu Search) algorithms will used to get the optimal values and parameters of our FLC. The ATS will based on a metaphor of social interaction. It searches a space by adjusting the trajectories of individual vectors, called 'particles', as they are conceptualized as moving as points in multidimensional space.

The ATS technique can generate a high quality solution within a shorter calculation time and have a stable convergence characteristic than other methods. The ATS algorithm will applied to search best Fuzzy control parameters. ATS will characterized as a simple concept, easy to implement, and computationally efficient. Unlike the other heuristic techniques, ATS has a flexible and well-balanced mechanism to enhance the global and local exploration abilities[4].

This paper presents investigations of speed control of a dc motor based on smooth trajectory tracking. A simulation environment will developed within Simulink and Matlab for evaluation of the control strategies. In this work, the dynamic model of the buck converter driven dc motor will derived in the state-space and transfer function forms. Two feedback control strategies, which are Fuzzy logic controller and the Ziegler-Nichols methods for tuning PID Controller, will developed in this simulation work. Performances of each controller will examined in terms of angular velocity, duty cycle input energy and armature current. Finally, a comparative assessment of the impact of each controller on the system performance will presented and discussed.

2. CONSTRUCTION OF DC MOTOR [2]

The equivalent circuit for a separately exited dc motor will show in Figure (1).

The equation describing the characteristics of a separately excited motor can be determined from Fig. (1), as

$$
\begin{aligned}
& V_{f}=R_{f} i_{f}+L_{f} \frac{d i_{f}}{d t} \\
& V_{\alpha}=R_{a} i_{a}+L_{a} \frac{d i_{\alpha}}{d t}+e_{g} \\
& T_{d}=J \frac{d W}{d t}+B W+T_{\mathbb{I}} \ldots
\end{aligned}
$$

Where

$\mathrm{W}=$ motor angular speed, or rotor angular frequency, radls. 
$\mathrm{B}=$ viscous friction constant, N.m $\mid \mathrm{rad} \backslash \mathrm{s} . K_{v}=$ voltage constant, V\A. radls

$L_{a}=$ armature circuit inductance, $\mathrm{H}$

$L_{f}=$ field circuit inductance, $\mathrm{H}$

$R_{a}=$ armature circuit resistance, $\Omega$

$R_{f}=$ field circuit resistance, $\Omega$

$T_{\mathbb{l}}=$ load torque, N.m

\section{CONTROL THE SPEED OF DC MOTOR [1]}

The speed of a separately excited DC motor can found from the Eq.

$w=\frac{\vec{V}_{\alpha}-R_{a} I_{\alpha}}{K_{v} I_{f}}$

We can notice from Eq. (4) that the motor speed can varied by:

-- Controlling the armature voltage $V_{\alpha}$, known as voltage control

-- Controlling the field current $I_{f}$, known as field control

-- Torque demand, which corresponds to an armature current

$I_{a}$, for a fixed field current $I_{f}$

In this paper, we use the buck convertor in order to control the armature voltage $V_{a}$.

\section{- Speed Control Unit [5]}

The buck converters modeling will use as speed control unit, the buck converter with ideal switching devices will considered here which is operating with the switching period of $\mathrm{T}$ and duty cycle $\mathrm{D}$ as in Fig. 2

In this paper, the duty cycle of the buck converter will change by using the Fuzzy-ATS controller.

\section{- $\quad$ Speed control method}

1. Open-loop control

A configuration of the open-loop control in a block diagram will show in fig.3. This method will used to change the output voltage of the converter according to set speed. This method is suitable for changing speed and can obtain high speeds. Simply when speed regulation with varying loads is not so much of a concern.

\section{Closed-loop control}

Fig.4 shows the block diagram configuration of the closedloop control system using the speed control unit. It will see that, the parameters of the Fuzzy -Controller as optimal results will find by using Fuzzy -ATS technique as intelligent optimization.

\section{REALIZATION OF A FUZZY-ATS CONTROLLER TUNING OPTIMAL PARAMETERS [6]}

\section{A. Design of Fuzzy Logic Controller}

Fig. (4) show block diagram of close-loop control system using fuzzy logic controller (FLC) to control the speed of single-phase induction motor.

Here the first input to the (FLC) is the speed error (e) and second is the change in speed error (ce) at sampling time ( $t_{g}$ ). The two input variables e ( $\left.{ }^{t_{g}}\right)$ and ce $\left({ }^{t_{s}}\right)$ will calculated at every sampling time as:
$\mathrm{e}\left(t_{g}\right)=w_{\gamma}^{*}\left(t_{g}\right)-w_{Y}\left(t_{g}\right)$

ce $\left(t_{g}\right)=\mathrm{e}\left(t_{g}\right)-\mathrm{e}\left(t_{g}-1\right)$

where ce denotes the change of error e, $w_{Y}^{*}\left(t_{s}\right)$ is the reference rotor speed, $w_{Y}\left(t_{g}\right)$ is the actual speed, $\mathrm{e}\left(t_{g}-1\right)$ is the value of error at previous sampling time. The output variable is the change in speed $\Delta \mathrm{w}$ which is integrated to get the reference speed as shown in the equation

$w_{Y}\left(t_{g}\right)=w_{Y}\left(t_{g}-1\right)+\Delta w$

The fuzzy logic controller consists of four blocks, Fuzzification, inference, knowledge base and Defuzzification.

\section{Fuzzification :}

In this stage the crisp variables of input e $\left(t_{g}\right)$ and ce $\left(t_{g}\right)$ are converted into fuzzy variables. The fuzzification maps the error and change in error to linguistic labels of fuzzy sets. Membership function is associated to each label with triangular shape that consists of two inputs and one output. The proposes controller uses following linguistic labels NB,NM,NS,ZE,PS,PM,PB. Each of the inputs and output contain membership function with all these seven linguistics.

2. Knowledge base and inference stage:

Knowledge base involve defining the rules represented as IFTHEN rules statements governing the relationship between input and output variables in terms of membership function.

In this stage the input variables e $\left(t_{s}\right)$ andce $\left(t_{s}\right)$ are processed by the inference mechanism that executes $7 * 7$ rules represented in rule table shown below. Considering the first rule, it will represented as IF change in speed error is NB and change in speed is NB, THEN the output will be NB. Here Madman's algorithm for inference mechanism used.

\section{Defuzzification:}

This stage introduces different methods that can be used to produce fuzzy set value for the output fuzzy variable $\Delta \mathrm{w}$.

Here the center of gravity or centroids method will used to calculate the final fuzzy value $\Delta \mathrm{w}\left(t_{s}\right)$. Defuzzification using COA method means that crisp output of $\Delta W^{*}\left(t_{g}\right)$ is obtained by using Centre of gravity, in which the crisp output $\Delta \mathrm{w}\left(t_{s}\right)$ variable is taken to be the geometric Centre of the output fuzzy variables value $\mu_{\text {out }}(\Delta \mathrm{w})$ area, where $\mu_{\text {out }}(\Delta \mathrm{w})$ is formed by taking the union of all the contributions of rules with the degree of fulfillment greater than zero. Then the COA expression with discretized universe of discourse can written as:

$$
\Delta w=\frac{\sum_{i=1}^{n} \Delta w_{i} \cdot \mu_{\text {out }}\left(w_{i}\right)}{\sum_{i=1}^{n} \mu_{\text {out }}\left(\Delta w_{i}\right)}
$$

The Membership Function of Fuzzy Variables $\mu_{\varepsilon}, \mu_{c e}$, and $\mu_{w v}$ are shown in figure (5), and the Fuzzy Controller Rule Base is shown in table (1) .

The Rules view and Surface view of fuzzy controller output will show in figure (8).

B. Fitness Function (FF) [1]

The most common performance criteria are integrated absolute error ( IAE ), the Integrated of Time weight square Error (ITSE) and integrated of Square Error (ISE) that can be evaluated analytically in frequency domain .

In the paper the IAE will used as fitness, function (FF) for evaluating the fuzzy controller performance, the performance criterion formula for IAE is as follow:

$$
\mathrm{IAE}=\int_{0}^{\mathrm{m}}|\mathbf{r}(\mathrm{t})-\mathrm{y}(\mathrm{t}) \mathrm{dt}|=\int_{0}^{\mathrm{s}}|\mathrm{e}(\mathrm{t}) \mathrm{dt}|
$$


A set of good controller parameters $K_{e}, K_{c e}, K_{w}$ can yield a good step response that will result in performance criteria minimization the FF in the time domain.

These performance criteria is include the over shoot, rise time, settling time, and steady state error.

\section{Scheduling ATS for Fuzzy Controller Parameters[7]}

An ATS Algorithms used to find the optimal parameters of the fuzzy controller to control the speed of DC motor. The structure of the fuzzy controller with ATS algorithm will show in fig. 5 .

\section{ADAPTIVE TABU SEARCH [4]}

The adaptive tabu search or ATS is the modified version of the TS. Based on iterative neighborhood search approach, the ATS was launched in 2004, The ATS search process begins the search with some random initial solutions belonging to a neighborhood search space. All solutions in neighborhood search space will evaluated via the objective function. The solution giving the minimum objective cost is set as a new starting point of next search round and kept in the tabu list (TL). Fig. 6 illustrates some movements of the ATS.

The ATS algorithm will summarized step-by-step as follows.

1. Initialize a search space $(\Omega), T L=0$, search radius $(\mathrm{R})$, count, and maximum radius (MAXR).

2. Select randomly an initial solution $S_{0}$ from a certain search space $\Omega$. Let $S_{0}$ be a current local minimum.

3. Generate randomly $\mathrm{N}$ solutions around $S_{0}$ within a search radius $\mathrm{R}$. Store the $\mathrm{N}$ solutions, called neighborhood, in a set $\mathrm{X}$.

4. Find the objective value of each member in $X$ via objective functions. Set $S_{1}$ as a member giving the minimum cost.

5. If $\mathrm{f}\left(\mathrm{S}_{1}\right)<\mathrm{f}\left(\mathrm{S}_{0}\right)$, put $S_{0}$ into the TL and set $S_{0} S_{1}$, otherwise, store $S_{1}$ in the TL instead.

6. When a local entrapment occurs, activate the BT mechanism,

7. If the termination criteria $(\mathrm{TC})$ : count $=$ count $\max$ or desired specification are met, then stop the search process. $S_{0}$ is the best solution, otherwise go to ( 8 ).

8. Invoke the adaptive radius (AR) mechanism, once the search approaches the local or the global solution to refine searching accuracy.

9. Update count $=$ count +1 , and go back to Step 2 .

The diagram in Fig. 7 reveals the search process of the ATS algorithm.

Fig.9 show the flow diagram of Fuzzy-ATS controller.

\section{THE ZIEGLER-NICHOLS METHODS FOR TUNING PID CONTROLLERS [8,9]}

To select the PID controller parameters $\mathrm{K} 1, \mathrm{Ti}$ and $\mathrm{Td}$ can be obtained by using the classical control system design techniques like Ziegler and Nichols methods. It have two empirical methods for obtaining the controller parameters, The Process Reaction Method and The Continuous Cycling Method.
The process Reaction Method: It is based on the assumption that the open loop step response of most process control systems has an S-shape, called the process reaction curve, as shown in Figure ( 10 ). The process reaction curve may be approximated to a time delay D and first order system of maximum tangent slope $\mathrm{R}$.

The process Reaction Method assumes that the optimum response for the closed loop system occurs when the closed loop-damping ratio has a value of 0.21 . The controller parameters, as function of $\mathrm{R}$ and $\mathrm{D}$, to produce this response, are given in Table 2 .

\section{SIMULATION RESULTS}

8. IMPLEMENTING ATS TUNING FOR FUZZY CONTROLLER:

The Simulation MATLAB to control the speed of DC motor using fuzzy-ATS controller with Inverter Speed Control Unit at reference speed as shown in figure (11), according to trials , the system must be in each examined iteration the adaptive tabu search algorithm search the optimal speed. Table ( 3 ) shows the ATS parameters' which used to verify the performance of fuzzy-ATS controller parameters

The simulation results are obtained for three second range time, The speed response of fuzzy controller tuning parameter using ATS strategy is shown in figure (12).

The Output performance of the system under no-load and fullload conditions as follow:

$\begin{array}{lll}\text { Rise time } & =0.137 \mathrm{~s} \\ \text { Maximum overshoot } & =0.03 \mathrm{v} \\ \text { Settling time } & =0.315 \mathrm{~S} \\ \text { Steady stat error } & =0.003\end{array}$

\section{COMPARISON BETWEEN ATS TUNING FUZZY CONTROLLER WITH ZIEGLER - NICHOLS CONTROLLER:}

A comparison is made to approach the effectiveness of the proposed, the performance comparison between fuzzy-ATS controller and Ziegler-Nichols controller as shown in table (4) and table (5).

The speed response of the Fuzzy-ATS Controller comparing with the speed response of the Ziegler-Nichols is shown in figure ( 13 ) \& figure (14)

\section{CONCLUSION}

In this paper, the speed of a DC Motor drive will controlled by means of two different controllers. The Fuzzy-ATS Controller and Ziegler-Nichols Controller. According to the results of the computer simulation, the Fuzzy-ATS Controller is the best controller that presented satisfactory performances and good robustness (no overshoot, minimal rise time, steady state error is 0 ). The major drawback of the fuzzy controller is insufficient analytical technique design (the selection of ke, kce, ko). We chose the one with the use of the ATS algorithm for the optimization of this controller in order to control DC motor speed. Finally, the proposed controller provides drive robustness improvement, gives very good results, and possesses good robustness. 


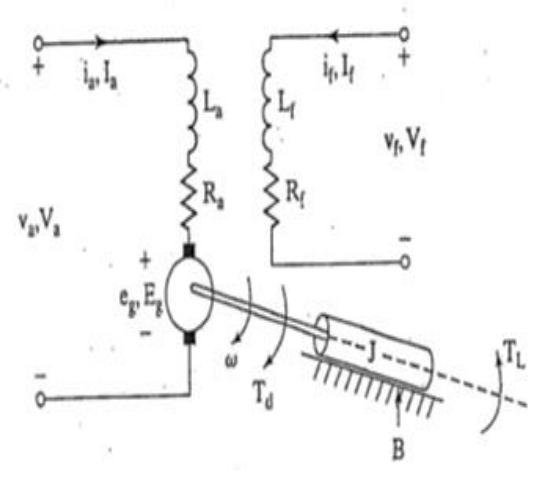

Fig. (1): Equivalent circuit of separately dc matar.

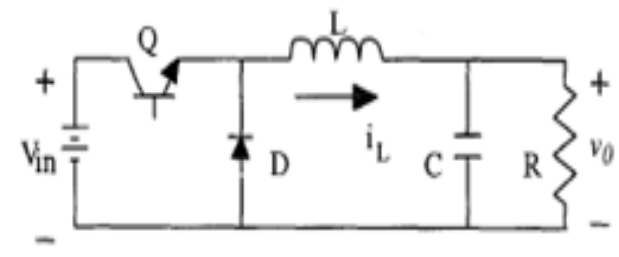

Fig. (2): DC-DC Buck Converter

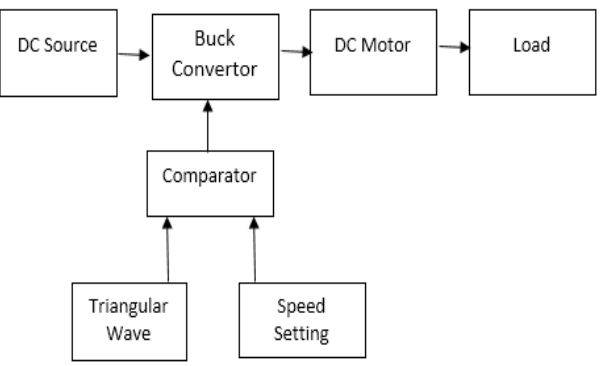

Fig. (3): Block diagram of open-loop control

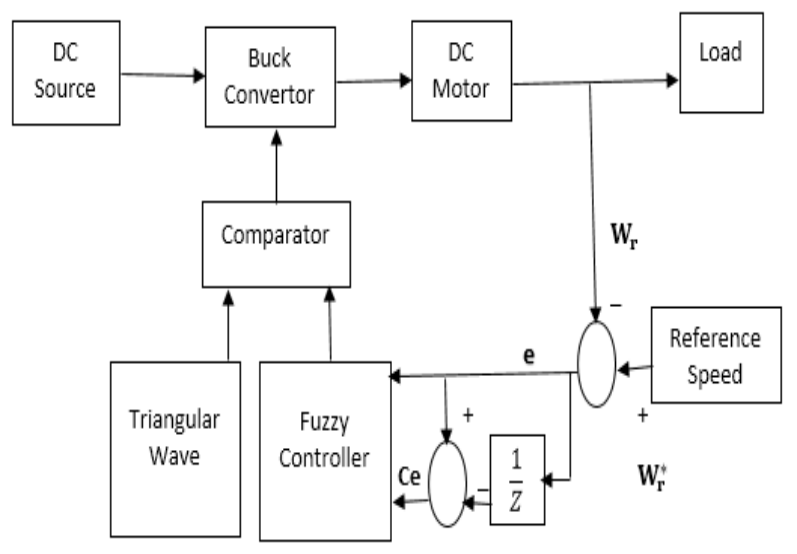

Fig. (4): Block diagram of closed-loop control

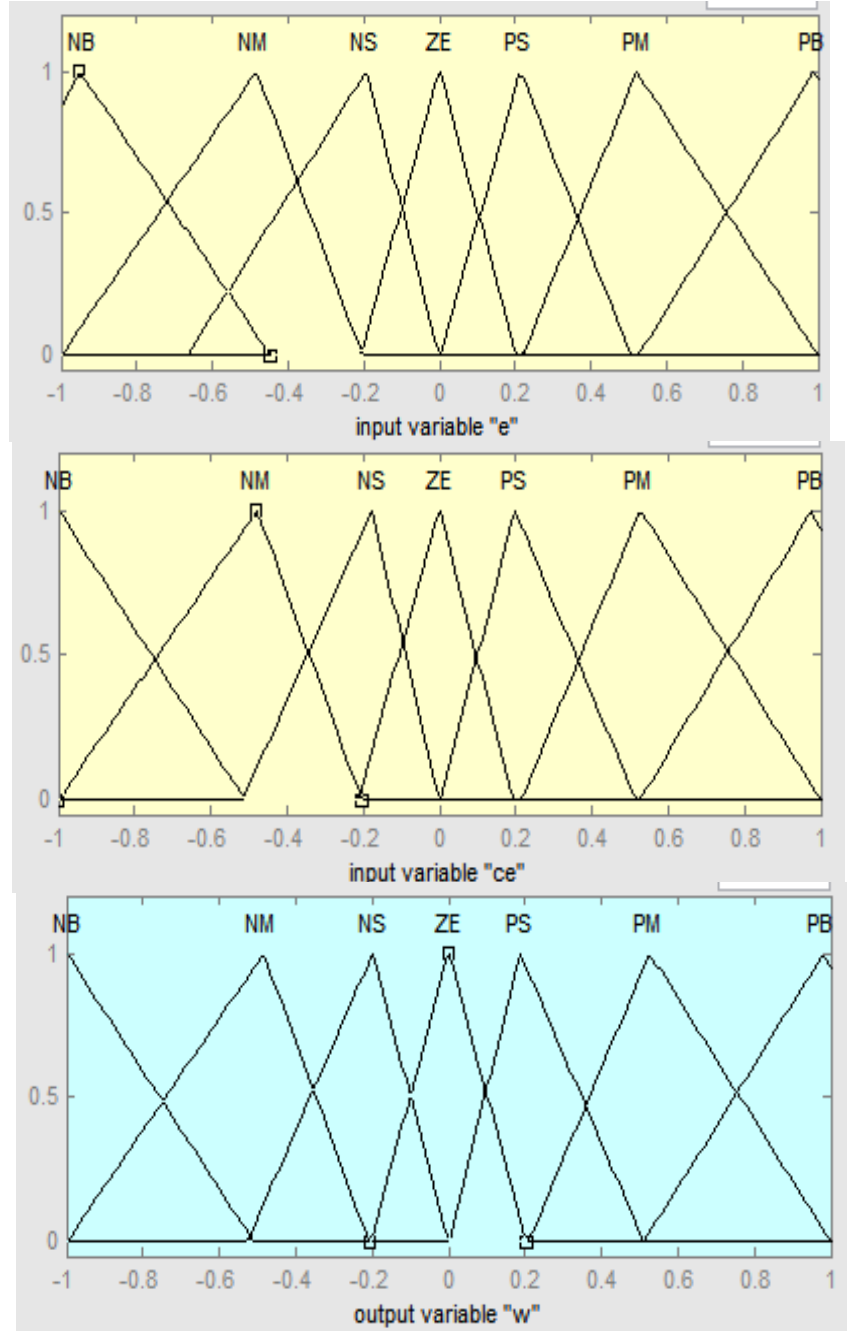

Fig. (5): Membership Function of Fuzzy Variables $\mu_{e}, \mu_{c e}$, and $\mu_{w}$

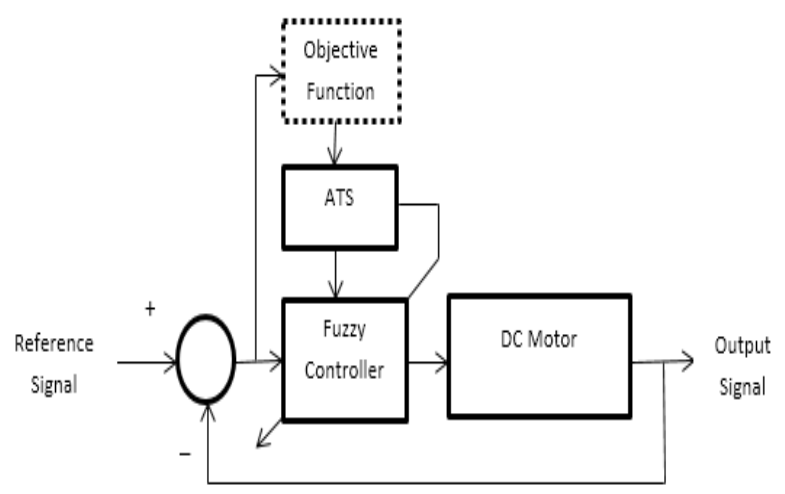

Fig. (6): Block diagram of proposed Fuzzy Controller with ATS Algorithm 


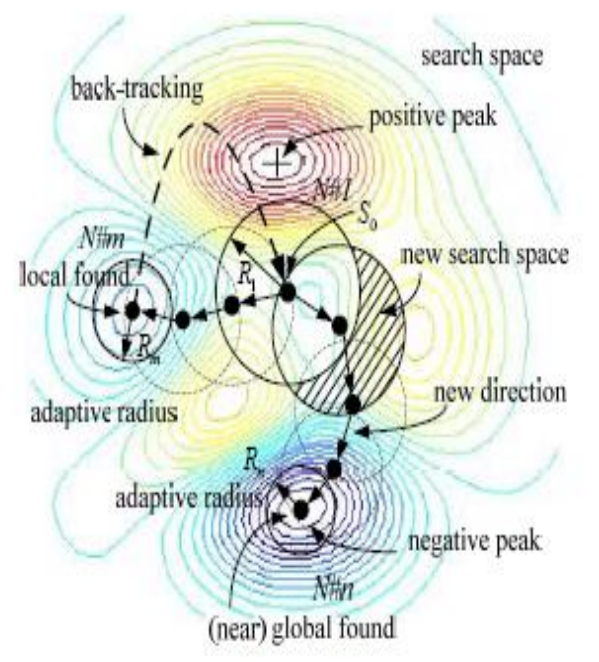

Fig. (7): Some movements of ATS

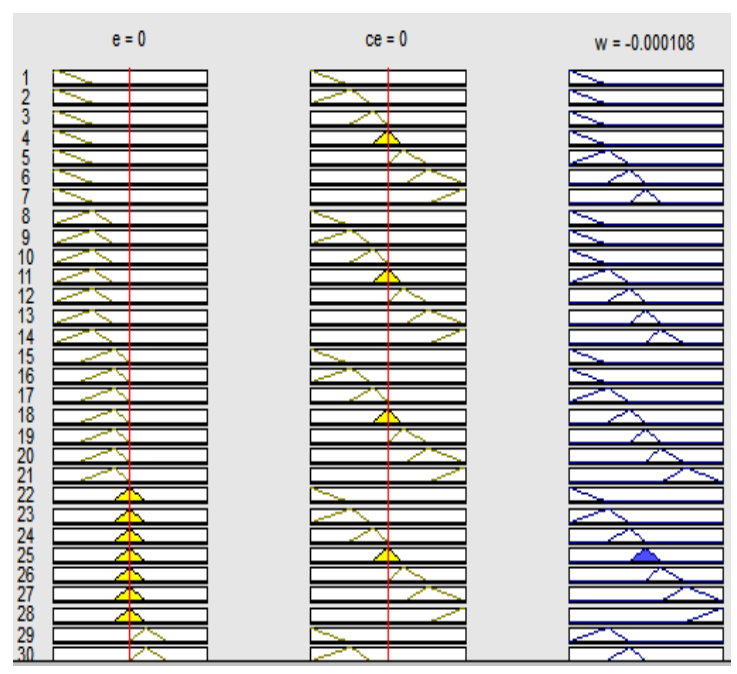

(a)

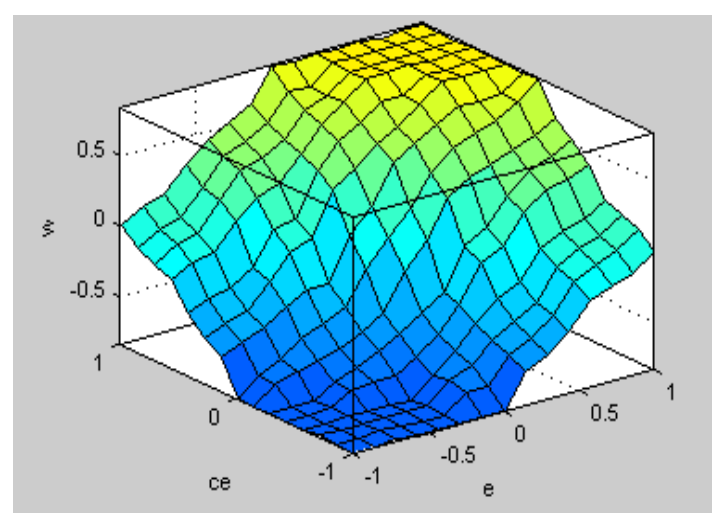

(b)

Fig. 8: (a) Rules view of fuzzy controller output (b) Surface view of fuzzy controller output

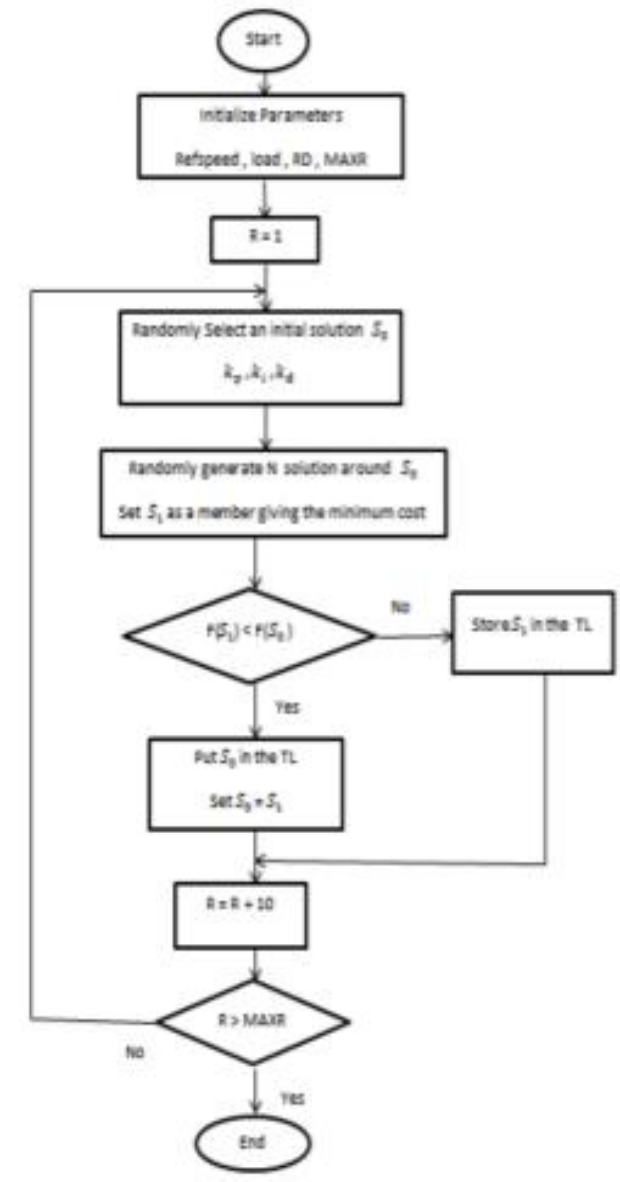

Fig. (9): Flow diagram of Fuzzv-ATS

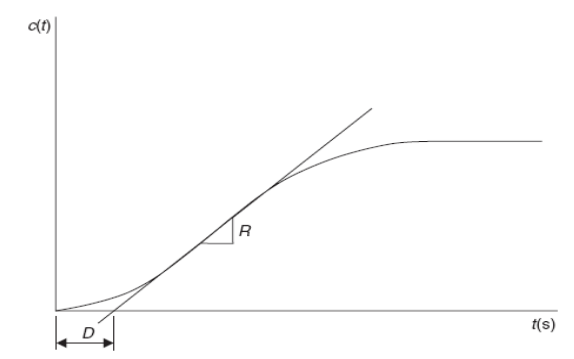

Fig. (10): Process reaction curve.

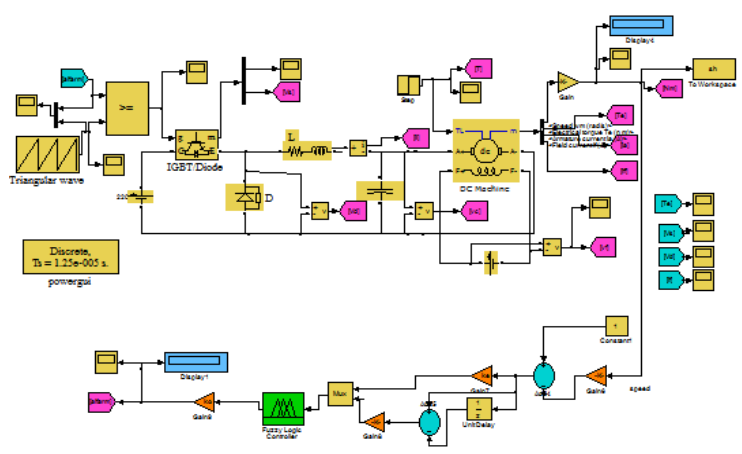

Fig. (11): Simulation MATLAB to control the speed of DC motor using fuzzv-ATS controller 


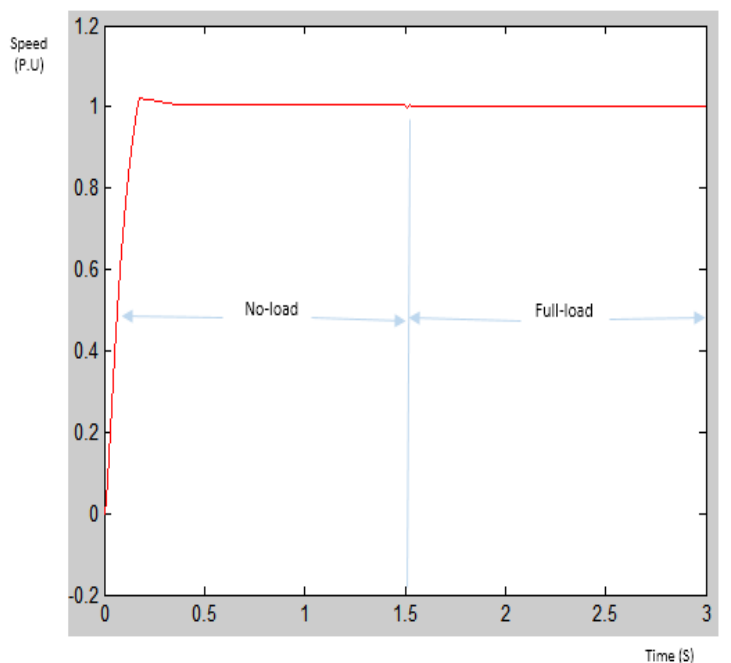

Fig. (12): Speed response of fuzzy Controller tuning parameter using ATS Strategy
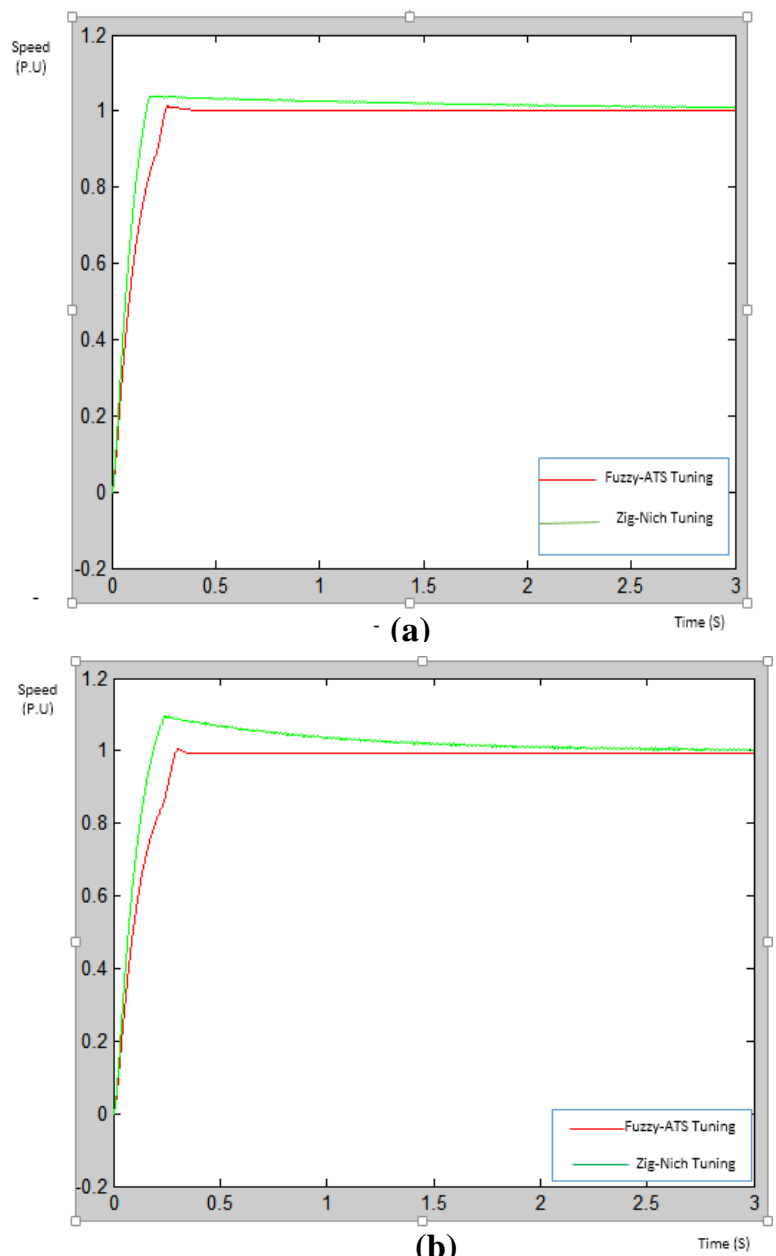

Fig. (13): Comparing performance of Fuzzy-ATS controller and Ziegler-Nichols Controllers at (a) Per-unit No-load, (b) per-unit full-

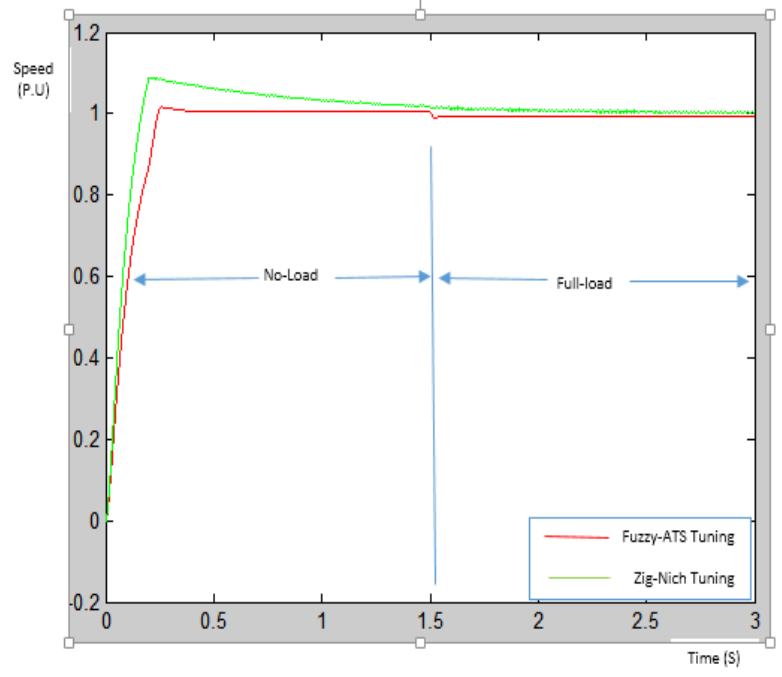

Fig.(14) Comparing performance e of FuzzyATS

controller and Ziegler-Nichols Controller

Table (1): Fuzzy Controller Rule Base

\begin{tabular}{|c|c|c|c|c|c|c|c|}
\hline $\begin{array}{c}\text { e(pu) } \\
\mathrm{ce}(\mathrm{pu})\end{array}$ & NB & NM & NS & ZE & PS & PM & PB \\
\hline NB & NB & NB & NB & NB & NM & NS & $Z$ \\
\hline NM & NB & NB & NB & NM & NS & Z & PS \\
\hline NS & NB & NB & NM & NS & $Z$ & PS & PM \\
\hline ZE & NB & NM & NS & $Z$ & PS & PM & PB \\
\hline PS & NM & NS & Z & PS & PM & PB & PB \\
\hline PM & NS & $Z$ & PS & PM & PB & PB & PB \\
\hline PB & $Z$ & PS & PM & PB & PB & PB & PB \\
\hline
\end{tabular}

Table (2): Ziegler - Nichols PID parameters using the Process Reaction Method
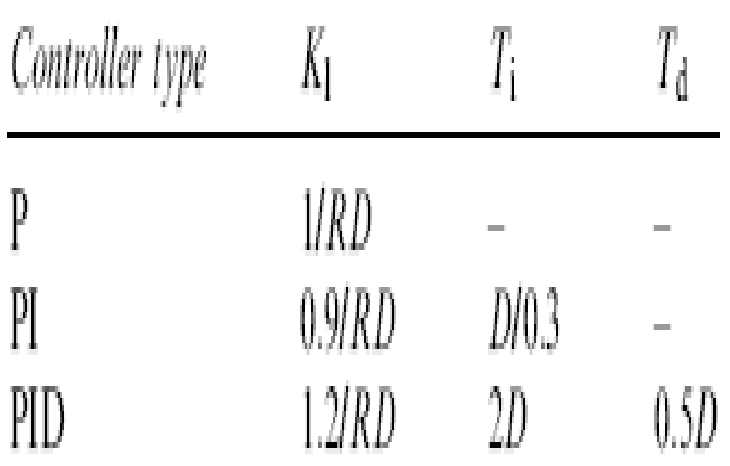
Table (3:) Parameters of ATS algorithm

\begin{tabular}{|c|c|}
\hline Number of neighborhood $(\mathbf{N})$ & 30 \\
\hline Population size & 3 \\
\hline Search radius (R) & 10 \\
\hline
\end{tabular}

Table (4): The set of good controller parameters $K_{e} K_{c e}$, $K_{o}$ for fuzzy-ATS controller and ${ }^{K_{p}} K_{i}, K_{d}$ for ZieglerNichols controller at No-load and Full-load.

\begin{tabular}{|c|c|c|c|}
\hline \multicolumn{2}{|c|}{ No-Load } & \multicolumn{2}{c|}{ Full-Load } \\
\hline Fuzzy-ATS & Zieg-Nich & Fuzzy-ATS & Zieg-Nich \\
Controller & Controller & Controller & Controller \\
\hline$K_{e=}$ & $K_{p}=$ & $K_{e}=10$ & $K_{p}=$ \\
13.968 & 11.4286 & & 31.5789 \\
\hline$K_{c e}=$ & $K_{i}=$ & $K_{c e}=$ & $K_{i}=$ \\
0.0105 & 5.7143 & $1.0000 \mathrm{e}-003$ & 39.4737 \\
\hline$K_{o=}$ & $K_{d=}$ & $K_{o}=1$ & $K_{d}=$ \\
0.8803 & 0.0571 & & 0.0632 \\
\hline
\end{tabular}

Table (5): The set of the Output performance of the response by fuzzy-ATS controller and Ziegler-Nichols controller at No-load and Full-load

\begin{tabular}{|c|c|c|c|c|}
\hline \multirow{2}{*}{ Results } & \multicolumn{2}{|c|}{ No-load } & \multicolumn{2}{c|}{ Full-load } \\
\cline { 2 - 5 } & $\begin{array}{c}\text { Fuzzy- } \\
\text { ATS } \\
\text { Controlle } \\
\text { r }\end{array}$ & $\begin{array}{c}\text { Zieg.- } \\
\text { Nich. } \\
\text { Controlle } \\
\text { r }\end{array}$ & $\begin{array}{c}\text { Fuzzy- } \\
\text { ATS } \\
\text { Controlle } \\
\text { r }\end{array}$ & $\begin{array}{c}\text { Zieg.- } \\
\text { Nich. } \\
\text { Controlle } \\
\text { r }\end{array}$ \\
\hline $\begin{array}{c}\text { Rise } \\
\text { time } \\
\text { (sec.) }\end{array}$ & 0.25 & 0.15 & 0.3 & 0.2 \\
\hline $\begin{array}{c}\text { Max. } \\
\text { Oversho } \\
\text { t }\end{array}$ & 0.005 & 0.05 & 0.01 & 0.1 \\
\hline $\begin{array}{c}\text { Settling } \\
\text { time } \\
\text { (Sec.) }\end{array}$ & 0.3 & 0.6 & 0.4 & 1 \\
\hline $\begin{array}{c}\text { Steady } \\
\text { state } \\
\text { error } \\
\text { (\%) }\end{array}$ & $0.004 \%$ & $0.006 \%$ & $0.003 \%$ & $0.005 \%$ \\
\hline
\end{tabular}

\section{REFERENCES}

[1] Alia J. Mohammed " A Particle swarm Optmization based optimum of tuning PID Controller for a Separately Excited DC Motor "Eng.\& Tech. Journal, Vol. 29, No. 16, 2011.

[2] R.M.T.Raja Ismail " Speed Control of buck-converter driven DC Motor using LQR and PI " International Conference on Information Management and Engineering, 2009.
[3] MUHAMMED H. RASHID " Power Electronics Circuits , Devices , and Applications " 2004 by Pearson Education, Inc. upper saddle river, NJ 07458.

[4] S.Suwannarongsri and D. Puangdownreong " Adaptive Tabu Search for Traveling Salesman Problems" International Journal of Mathematics and Computer in Simulation . Issue 2. Volume 6. 2012.

[5] Mohamed Assaf " DC-DC Converters Via MATLAB / SIMULINK " Acta Polytechnica Hingarica, Vol. 8, No. 6, 2011.

[6] Boumediene Allaoua " The Efficiency of Particle Swarm Optimization Applied of Fuzzy logic DC Motor Speed Control" Serbian Journal of electrical engineering. Vol. 5, No.2, 2008, 247-262.

[7] Wai Phyo Aung " Analysis on Modeling and Simulink of DC Motor and its Driving System used for wheeled Mobile Robot " Proceedings of world acabemy of science, Volume 26 December 2007, issn 2070-3740.

[8] Omer Ghanayem " PID Plus Fuzzy Controller Structures as a design base industrial applications " Prentice - Hall International, Inc., 1989.

[9] Roland S.Burns "Advanced Comtrol Engineering "PLANT A TREE. Typest in india by Software Serrices Pvt. Ltd. 2001

\section{AUTHOR'S PROFILE}

Amer Mohammad Jarjees was born in Mosul, Iraq in1962. $\mathrm{He}$ received the B.Eng. degree in electrical engineering from Bagdad University in 1985, The Higher Diploma degree in communication engineering from University of Technology Al-Rasheed College of Engineering \&Science in 1989. The M. Eng. Degree in Control Engineering from Mosul University in 2013.

Since 2006, he has been with the University of Technology, Department of laser engineering. Since 2008, he has been with the Electrical engineering of Mosul University.

His research interests in optimization, power electronics and intelligent Control. amerpapper@gmail.com

Omar Turath Tawfeeq. B.Sc in Electrical Engineering /Power and Machines from University of Mosul in 2003with grade Good and The rank is First. MSc in Electrical Engineering / Power and Machines from Electrical Eng. Dept./College of Engineering /University of Mosul in 2006 with grade V. Good. Member, Iraqi Engineering Society Currently he is lecturer at the Department Electrical Engineering, University of Mosul since 2006.

omarturath@yahoo.com

Ali Abbawi Mohammed Alabbawi, Mosul-IRAQ, University of Mosul, College of Engineering, Electrical Engineering Department.

B.Sc in Electrical Engineering /Power and Machines from University of Mosul in 2006 The rank is Second. MSc in Electrical Engineering / Power and Machines/ Control System from Electrical Eng. Dept./College of Engineering/University of Mosul in 2013 with grade V. Good. Assist lecturer at the Department of Electrical Engineering, University of Mosul since 2013.. ALIali_abwi@yahoo.com 